\author{
Olivier Joannes-Boyau \\ Patrick M. Honoré \\ Willem Boer \\ Thomas Rose
}

\section{Septic acute kidney injury and tubular apoptosis: never a Lone Ranger}

Received: 8 September 2009

Accepted: 30 October 2009

Published online: 19 November 2009

(C) Copyright jointly hold by Springer and ESICM 2009

This editorial refers to the article available at: doi:10.1007/s00134-009-1723-x.

O. Joannes-Boyau

Haut Leveque University Hospital of Bordeaux,

University of Bordeaux 2, Pessac, France

P. M. Honoré · T. Rose (凶)

ICU High and Medium Care, Burn Center,

Queen Astrid Military Hospital, Rue Bruyn, 1,

1120 Brussels (Neder-over-Heembeek), Belgium

e-mail: Patrick.honore@mil.be; Pathonor@ skynet.be

Tel.: +322-264-4848

Fax: $+322-262-1480$

W. Boer

Nephrology and Intensive Care Medicine Departments, Atrium Medical Center, Heerlen, The Netherlands

T. Rose

Universitair Ziekenhuis Brussels,

Free University of Brussels, Brussels, Belgium

Until recently, acute kidney injury (AKI) in intensive care was, on the whole, considered to be a condition of haemodynamic origin and, consequently, nearly all efforts were concentrated on increasing renal flow by increasing cardiac flow and perfusion pressure [1]. In this context, AKI was thought to be a result of low renal blood flow, induced by either cardiogenic shock or distributive (septic) shock, or both. Early in this decade, Bellomo's group presented data shedding new light on the animal model of septic AKI. These researchers found that renal blood flow, both medullar and cortical, is maintained and even increases during severe septic shock [2], thereby undermining earlier concepts and definitively demonstrating that septic AKI is a totally different physiological phenomenon to non-septic AKI. In an even earlier study, Hotchkiss et al. demonstrated that apoptosis-and not necrosis alone-plays an important role in sepsis and septic shock [3]. Despite these findings and although animal models provided substantial advances in the elucidation of the aetiology of lesions such as tubular apoptosis [4], debate remained ongoing whether apoptosis really played a key role in mechanisms of organ dysfunction in humans [5]. This debate is clearly reflected by the authors of the study on the histopathological features of AKI, which has recently been published in this journal [6]. In their introduction, the authors state that there is a paucity of histopathological data in humans and that most of the data currently available were published in studies carried out before the 1980s [6]. In their study, these authors compared kidney biopsies taken early post-mortem in 19 consecutive patients dying from septic shock with biopsies taken from eight dead trauma patients and nine dead patients without sepsis with only mild renal dysfunction [6].

It is clear from the data that acute tubular apoptosis was present in the cases of septic AKI, whereas nearly no apoptosis could be seen in the non-septic controls. Apoptosis was further confirmed using three different techniques in the study: (1) routine microscopy; (2) the so-called TUNEL technique (terminal-deoxynucleotidyltransferase-mediated dUTP-digoxigenin nick and labeling); (3) activated caspase-3 labelling. The two last techniques detected significantly more apoptosis in the septic group than in the other two groups ( $p$ value $<0.0001 ; 6 \%$ apoptosis in the septic group vs. $1 \%$ in the non-septic group), which represents the major strength of this study. However, one could conclude that the overall 
percentage of patients found to have apoptosis in septic AKI remains low if apoptosis actually does play a major role. One subset of controls consisted of biopsies from trauma patients who died at scene of trauma, thereby limiting the possibility of any type of histological lesions developing in the kidney. The biopsies on these dead trauma patients were performed relatively late in comparison to those on the other control cases and the study group, undoubtedly opening speculation for bias. The second subset of six other control cases consisted of outof-hospital cardiac arrest patients. In all six of these patients, treatment was withdrawn for neurological reasons while, on average, serum creatinine values were only mildly increased. The control biopsies were therefore performed in patients with no or only limited renal dysfunction, detracting from the specific conclusions drawn regarding the histopathology of septic AKI. A further drawback of the study could be that all biopsies studied were cadaveric, which limited the study of any possible reversible changes that would be undoubtedly seen in the natural history of the patients who improve. Finally, the fact that some control groups were historical controls can also be seen as a drawback to the conclusions drawn.

From a theoretical point of view, necrosis results from the additive effect of a number of independent biochemical events that are activated by the severe depletion of cell energy stores. In contrast, apoptosis occurs via a coordinated, predictable, and pre-determined pathway. These biochemical differences between apoptosis and necrosis have important therapeutic implications. Once a cell has been severely injured, necrosis is difficult to prevent. In contrast, the apoptotic pathway can potentially be modulated to maintain cell viability [7]. The components of the apoptotic pathway that are potentially amenable to therapeutic modulation are numerous-at least in theory [8]. In this new therapeutic avenue for septic AKI or apoptotic-inflammatory AKI, the administration of caspase inhibitors (CI) seems to be taking on a role of increasing importance. Indeed, CI ameliorates ischaemia-reperfusion injury in multiple organs, including the kidney. However, the extent to which this protective effect of caspase inhibition is caused by reduced (intra-renal) inflammation or by amelioration of renal tubular cell loss due to apoptosis remains a source of uncertainty [9]. In addition to caspase inhibition, the apoptotic pathway offers many potential targets for therapeutic interventions that are aimed at preventing renal tubular cell apoptosis. All of these inhibitors likely reduce renal function impairment. Using a model of glycerolinduced AKI in rats (Gly-AKI), Homsi et al. [10] found that caspases participate in important pathogenic mechanisms in Gly-AKI, such as inflammation, apoptosis, vasoconstriction and, finally, tubular necrosis. The early inhibition of caspases attenuates these mechanisms and reduces the renal function impairment in the Gly-AKI rat model [10]. It has also been demonstrated that apoptosis occurs in the kidney during lipopolysaccharide (LPS)induced AKI (LPS-I-AKI). However, the relative importance of apoptosis in LPS-I-AKI remains unproven.

Based on the key role of the caspase enzyme cascade in the development of apoptosis, Guo and co-workers [11] hypothesized that treatment with a CI would protect mice from LPS-I-AKI. These researchers chose a study format whereby mice first received an injection of LPS and then were either treated with the broad-spectrum CI or remained untreated. They concluded that caspase inhibition may indeed protect against LPS-I-AKI, not only by preventing apoptotic cell death but also by inhibiting inflammation [11]. They further hypothesized that apoptotic kidney cells may even be a source of local inflammation leading to subsequent non-apoptotic renal injury [11]. Another recent study [12] showed that plasma from septic burn patients with AKI can initiate proapoptotic effects and functional alterations in renal tubular cells and podocytes in vitro that correlate with the degree of proteinuria and renal dysfunction. In this model, sepsis and burn had additive or even synergistic effects. This latter study certainly warrants further research on the effect of therapeutic interventions in several areas, such as the binding and elimination of the source of endotoxin by extracting the source of sepsis, the blocking of various apoptotic pathways, or even the extracorporeal removal of circulating toxic mediators using high-volume haemofiltration, high permeability haemofiltration, and coupled plasma filtration with adsorption [13]. In a very recent study [14], extracorporeal therapy with polymyxin B reduced the pro-apoptotic activity of the plasma of septic patients on cultured renal cells. These data provide further confirmation of the role of apoptosis in the development of sepsis-related AKI [14]. It seems likely that plasma separation techniques can prove beneficial in treating renal injury through the removal of pro-apoptotic factors and cytokines, although the role of type, dose, and timing of conventional renal replacement strategies [13] seems equivocal in the light of the recent publication of two large continuous renal replacement therapy (CRRT) studies conducted in the Intensive Care Unit $[15,16]$.

It is noteworthy that the authors of the article under discussion [6] arrive at different conclusions than those of a recent systematic review of studies on the same topic (the Bellomo group [17]). The authors of the review conclude that there are no consistent renal histopathological changes in human or experimental septic AKI. In fact, the majority of studies reviewed reported normal histology or only mild, nonspecific changes, while acute tubular necrosis (ATN) was relatively uncommon [18]. Bellomo et al. also conclude that renal lesions in septic shock go beyond those associated with simple acute tubular injury, notably capillary leukocytic infiltration and apoptosis. In both, the heterogenicity of the lesions is apparent. When we take into consideration the clinical history of the septic AKI group as described in the article 
of Lerolle et al. [6], it seems unlikely that the etiology for their renal dysfunction is solely of septic origin as haemodynamic instability is described in many of these patients. If we consider septic AKI to be a disease entity in which haemodynamic characteristics are no longer a mainstay, it seems reasonable to assume that revision of the concept of pre-renal AKI can be expected. In such patients, several assumptions associated with the 'prerenal azotemia paradigm' will be in violation of this revised definition. There is no evidence that ATN is the sole histopathological substrate of septic AKI and, above all, there is no evidence that urine tests can discriminate functional from structural AKI. Given that septic AKI in critically ill patients now accounts for close to $50 \%$ of cases of severe ICU-AKI in developed countries, this concept seems erroneous as volume loading no longer seems appropriate in this condition while treating cases of septic AKI. Indeed, once the patient has been adequately volume loaded, i.e. to euvolemia, and the patient then remains hypotensive, a further fluid challenge will not increase the already increased renal output; rather, it may harm the patient [19].

In a recent experiment, a novel avenue was explored. The renal protective effect of ghrelin was associated with an inhibition of the pro-inflammatory cytokines, particularly the suppression of tumor necrosis factor-alpha in both the circulation and the kidney tissues. Thus, ghrelin may be a promising peptide in managing endotoxemiainduced AKI [20]. While further evidence confirming the findings reported by Lerolle et al. [6] are necessary, the findings themselves provide justification for future studies looking specifically at the treatment of septic AKI. Interest in the caspase cascade specifically, as well as in local renal inflammation pathways in their entirety, and modes of intervention in both seem to be the way forward. Last but not least, the type of vasopressors used during resuscitation may have also an impact on apoptosis. During well-resuscitated septic shock after porcine peritonitis, low-dose arginine vasopressin, as compared to noradrenaline, appears to be the safer treatment with respect to decreased kidney damage through its action in reducing kidney tubular apoptosis and systemic inflammation [21].

In conclusion, there are exciting potential developments on many fronts. Revision of outdated concepts, with subsequent regime changes, seem likely in the light of recent histological findings. Intervention in inflammatory pathways, both directly and by the optimalization of plasma separation techniques, promises to be rewarding. Changes in fluid regimes and the vasopressor used in resuscitation merit further investigation in septic AKI. The early detection of renal dysfunction using new biomarkers will have a direct effect on intervention and will change clinical practice. Given the higher mortality rates in septic AKI than in non-septic AKI [22], the individualization of therapy [23], where necessary the implementation of more intensive techniques, may be required in some situations [24, 25], perhaps also in septic AKI [13]. Clinical practice may soon be changing... 'Lock, stock and barrel'.

\section{References}

1. Schrier RW, Wang W (2004) Acute renal failure and sepsis. $\mathrm{N}$ Engl $\mathrm{J}$ Med 351:159-169

2. Wan L, Bagshaw SM, Langenberg C, Saotome T, May C, Bellomo R (2008) Pathophysiology of septic acute kidney injury: what do we really know? Crit Care Med 36:198-203

3. Hotchkiss RS, Swanson PE, Freeman BD, Tinsley WK, Cobb JP, Matuschak GM, Bunchman TG, Karl IE (1999) Apoptotic cell death in patients with sepsis, shock, and multiple organ dysfunction. Crit Care Med 27:1230-1251

4. Bellomo R, Wan L, Langenberg C, May C (2008) Septic acute kidney injury: new concepts. Nephron Exp Nephrol 4:95-100

5. Abraham E, Singer M (2007) Mechanisms of sepsis-induced organ dysfunction. Crit Care Med 35:2408-2416
6. Lerolle N, Nochy D, Guérot E,Bruneval P, Fagon J-Y, Diehl J-L, Hill G (2009) Histopathology of septic shock induced renal injury: apotosis and leukocytic infiltration. Intensive Care Med. doi: 10.1007/s00134-009-1723-x

7. Devarajan P (2005) Cellular and molecular derangements in acute tubular necrosis. Curr Opin Pediatr 17:193-199

8. Rana A, Sathyanarayana P, Lieberthal W (2001) Role of apoptosis of renal tubular cells in acute renal failure: therapeutic implications. Apoptosis 6:83-102

9. Boneggio R, Lieberthal W (2002) Role of apoptosis in the pathogenesis of acute renal failure. Curr Opin Nephrol Hypertens 11:301-308

10. Homsi E, Janino P, de Faria JB (2006) Role of caspases on cell death, inflammation, and cell cycle in glycerol-induced acute renal failure. Kidney Int 69:1385-1392
11. Guo R, Wang Y, Minto AW, Quigg RJ, Cunningham PN (2004) Acute renal failure in endotoxemia is dependant on caspase activation. J Am Soc Nephrol 15:3093-3102

12. Mariano F, Cantaluppi V, Stella M, Romanazzi GM, Assenzio B, Cairo M, Biancone L, Triolo G, Ranieri VM, Camussi G (2008) Circulating plasma factors induce tubular and glomerular alterations in septic burns patients. Crit Care 12:R42

13. Honore PM, Joannes-Boyau O, Boer W, Collin V (2009) High-volume hemofiltration in sepsis and SIRS: current concepts and future prospects. Blood Purif 28:1-11

14. Cantaluppi V, Assenzio B, Pasero D, Romanazzi GM, Pacitti A, Lanfranco G, Puntorieri V, Martin EL, Mascia L, Monti G, Casella G, Segoloni GP, Camussi G, Ranieri VM (2008) Polymyxin-B hemoperfusion inactivates circulating proapoptotic factors. Intensive Care Med 34:1638-1645 
15. VA/NIH Acute Renal Trial Network, Palevsky PM, Zhang JH, O'Connor TZ, Chertow GM, Crowley ST, Choudoury D, Finkel K, Kellum JA, Paganini E, Schein RM, Smith MW, Swanson KM, Vijayan A, Watnick S, Star RA, Peduzzi P (2008) Intensity of renal support in critically ill patients with acute kidney injury. N Engl J Med 359:7-20

16. RENAL Replacement Therapy Study Investigators, Bellomo R, Cass A, Cole L, Finfer S, Gallagher M, Lo S,

McArthur C, McGuinness S, Myburgh J, Norton R, Scheinkestel C, Su S (2009) Intensity of continuous renalreplacement therapy in critically ill patients. N Engl J Med 361:1627-1628

17. Langenberg C, Bagshaw SM, May CN, Bellomo R (2008) The histopathology of septic acute kidney injury: a systematic review. Crit Care 12:R38

18. Bellomo R, Bagshaw S, Langenberg C, Ronco C (2007) Pre-renal azotemia: a flawed paradigm in critically ill septic patients? Contrib Nephrol 156:1-9
19. Honore PM, Joannes-Boyau O, Collin V, Boer W, Jennes S (2009) Continuous hemofiltration in 2009: what is new for clinicians regarding pathophysiology, preferred technique and recommended dose? Blood Purif 28:135-143

20. Wang W, Bansal S, Falk S, Ljubanovic D, Schrier RW (2009) Ghrelin protects mice against endotoxemia-induced acute kidney injury. Am J Physiol Renal Physiol (Epub ahead of print)

21. Simon F, Giucidi R, Scheurle A, Groger M, Asfar P, Vogt JA, Wachter U, Pioner F, Georgieff M, Moller P, Laporte R, Radermacher P, Calzia E, Hauser B (2009) Comparison of cardiac, hepatic, and renal effects of arginine vasopressin and noradrenaline during porcine fecal peritonitis: a randomized controlled trial. Crit Care 13:R113

22. Parmar A, Langenberg C, Wan L, May CN, Bellomo R, Bagshaw SM (2009) Epidemiology of septic acute kidney injury. Curr Drug Targets [Epub Ahead of Print]
23. Palevsky PM, O'Connor TZ, Chertow GM, Crowley ST, Zhang JH, Kellum JA (2009) Intensity of renal replacement therapy in acute kidney injury: perspective from within the Acute Renal Failure Trial Network Study. Crit Care 13:310

24. Ronco C, Cruz D, Oudemansvan-Straaten HM, Honoré PM, House A, Bin D, Gibney N (2008) Dialysis dose in acute kidney injury: no time for therapeutic nihilism-a critical appraisal of the Acute Renal Failure Trial Network study. Crit Care 12:308

25. Ridel C, Balde MC, Rondeau E, Vinsonneau C (2009) Dose of dialysis in intensive care unit. Reanimation 18:385-396 